IdeAs

Idées d'Amériques

15 | 2020

Eau et gestion de l'eau dans les Amériques

\title{
Eventos e episódios pluviais extremos: a configuração de riscos hidrometeorológicos em Curitiba (Paraná - Brasil)
}

Extreme rain events and episodes: the configuration of hydrometeorological risks in Curitiba (Paraná - Brazil)

Événements et épisodes de pluie extrême : la configuration des risques

hydrométéorologiques à Curitiba (Paraná - Brésil)

Eventos y episodios de lluvia extrema: la configuración de los riesgos

hidrometeorológicos en Curitiba (Paraná - Brasil)

\section{Gabriela Goudard e Francisco de Assis Mendonça}

\section{OpenEdition}

\section{Journals}

Edição electrónica

URL: http://journals.openedition.org/ideas/8082

DOI: $10.4000 /$ ideas.8082

ISSN: $1950-5701$

\section{Editora}

Institut des Amériques

\section{Refêrencia eletrónica}

Gabriela Goudard e Francisco de Assis Mendonça, «Eventos e episódios pluviais extremos: a configuração de riscos hidrometeorológicos em Curitiba (Paraná - Brasil) », IdeAs [Online], 15 | 2020, posto online no dia 01 março 2020, consultado o 25 março 2020. URL : http:// journals.openedition.org/ideas/8082 ; DOI : https://doi.org/10.4000/ideas.8082

Este documento foi criado de forma automática no dia 25 março 2020

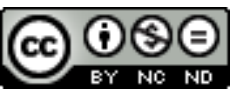

IdeAs - Idées d'Amériques est mis à disposition selon les termes de la licence Creative Commons Attribution - Pas d'Utilisation Commerciale - Pas de Modification 4.0 International. 


\section{Eventos e episódios pluviais extremos: a configuração de riscos hidrometeorológicos em Curitiba (Paraná - Brasil)}

Extreme rain events and episodes: the configuration of hydrometeorological risks

in Curitiba (Paraná - Brazil)

Événements et épisodes de pluie extrême : la configuration des risques

hydrométéorologiques à Curitiba (Paraná - Brésil)

Eventos y episodios de lluvia extrema: la configuración de los riesgos

hidrometeorológicos en Curitiba (Paraná - Brasil)

Gabriela Goudard e Francisco de Assis Mendonça

Agradecimentos

Á CAPES/Ministério da Educação do Brasil pelo suporte financeiro desta pesquisa.

\section{Introdução}

1 Os riscos climáticos encontram-se presentes na pauta dos temas da ciência desde longa data, configurando-se como componentes onipresentes e inerentes da sociedade moderna (Beck U., 2008; Almeida L., 2010). Contudo, na atualidade, estes processos vêm se destacando, sobretudo, mediante a concentração humana nas cidades e a severa insegurança em face dos cenários de possíveis mudanças climáticas globais e seus impactos nas diversas regiões do mundo.

2 A compreensão dos riscos reveste-se de grande importância em face dos prognósticos de mudanças do clima -unânimes que são na crença de intensificação das temperaturas do planeta e dos impactos de extremos climáticos-, quer seja pela necessidade de entendimento das complexidades inerentes ao sistema atmosférico (habitualidades e 
excepcionalidades), quer seja pela análise conjugada destes processos às dinâmicas de ocupação do espaço e de exposição das populações aos riscos (condições de vulnerabilidade) (IPCC, 2007; 2013; Mendonça F., 2010).

3 No Sul do Brasil, região na qual se insere a cidade de Curitiba (Figura 1), os principais desastres naturais configuram-se como sendo aqueles de origem pluvial (Monteiro C., 1991; EM-DAT, 2015; Silveira W et al., 2009), com destaque para as inundações urbanas. Dessa forma, modificações nos padrões de variabilidade pluvial e de extremos climáticos, em decorrência de possíveis mudanças climáticas globais, potencializam condições de perigo e riscos associados a estas dinâmicas.

Partido destas premissas, faz-se necessário compreender a variabilidade dos eventos extremos (condições discrepantes de um padrão habitual do clima), os episódios pluviais extremos (impactos atrelados às inundações, enchentes e alagamentos) e a configuração dos riscos hidrometeorológicos (Armond N., 2014; Goudard G., 2015; 2019).

Ressalta-se que no contexto deste artigo, os riscos são compreendidos como resultantes de uma construção social, na qual as condições físicas da natureza não se configuram como determinantes, de maneira isolada, mas interagem com as ações humanas (Dauphiné A., 2001; Dubois-Maury J., 2004; Veyret Y., 2007). Além disso, são abordados em sua dimensão hidrometeorológica (Goudard G., 2019), partindo-se dos pressupostos das interações entre as dinâmicas atmosféricas (meteorologia dos extremos pluviais tempestades, chuvas concentradas), suas repercussões em processos hidrológicos (episódios pluviais extremos - inundações, enchentes e alagamentos) e os impactos na sociedade (exposições das populações perante as condições de riscos). A suscetibilidade é considerada como as condições físico-naturais que favorecem o acúmulo de água, potencializando a ocorrência de inundações, ao passo que a vulnerabilidade se refere ao grau de exposição das populações às condições de risco (Goudard G., 2019).

Figura 1 Localização do município de Curitiba.

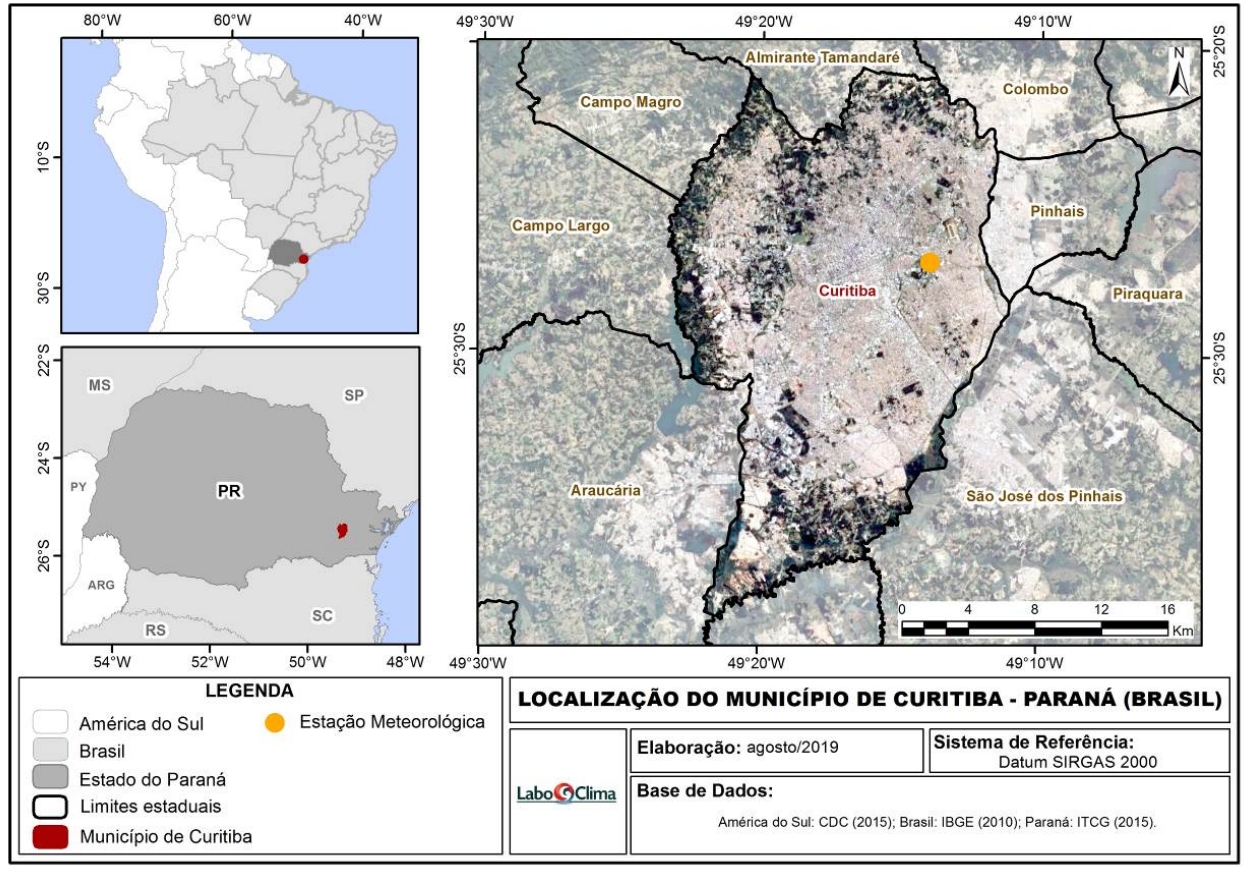

Organização: Goudard (2019) 
6 Partindo-se destes pressupostos e levando-se em consideração a relevância da temática, o presente artigo propõe-se a colocar em evidência um estudo de caso na cidade de Curitiba, destacando as condicionantes climáticas atreladas à ocorrência de eventos e episódios extremos, as zonas de inundação e as áreas de vulnerabilidade perante a estes processos. Além disso, o estudo permite evidenciar os desafios da abordagem dos riscos em ambientes urbanos, bem como as suas potenciais aplicações do ponto de vista da gestão.

7 Para tanto, as análises desenvolvidas sustentam-se nos pressupostos da Climatologia Geográfica, especificamente o Sistema Clima Urbano - S.C.U. (Monteiro C., 1976) e Sistema Ambiental Urbano - S.A.U. (Mendonça F., 2004), os quais, em conjunto, possibilitam realizar abordagens integradas das excepcionalidades climáticas (natural) e seus impactos no ambiente urbano (social e construído).

\section{Métodos e técnicas empregados na pesquisa}

8 No intuito de evidenciar as condições de riscos ligados às chuvas na cidade de Curitiba, os seguintes procedimentos foram executados:

\section{Caracterização dos eventos pluviais extremos}

Os eventos extremos de chuva foram identificados a partir de dados pluviais diários da estação meteorológica de Curitiba (2549006 - Figura 1) no período de 1980 a 2015, sendo estes provenientes do banco de dados Hidroweb - Sistemas de Informações Hidrológicas da Agência Nacional de Águas (ANA).

O limiar correspondente aos extremos pluviais foi determinado a partir do parâmetro percentil 99, sendo este corresponde a $48,6 \mathrm{~mm} / 24 \mathrm{~h}$ para a temporalidade supracitada e representando $1 \%$ das precipitações mais expressivas da série histórica de dados. A escolha deste limiar pautou-se em recomendações do ETCCDMI - Expert Team on Climate Change Detection and Indices, bem como em estudos de Pinheiro G. (2016) e Goudard G. (2015; 2019), que demonstraram boas aplicações deste parâmetro para a compreensão de eventos extremos e seus impactos na cidade de Curitiba.

11 Posteriormente à identificação, estes eventos foram caracterizados quanto à frequência, relativa ao número de dias de chuva iguais ou superiores ao percentil 99 e em relação as condições sinóticas, através de Cartas Sinóticas da Marinha do Brasil e imagens de satélite do Centro de Previsão do Tempo e Estudos Climáticos (CPTEC), visando identificar a gênese climática associada as excepcionalidades pluviais na área de estudo.

\section{Identificação dos impactos de episódios pluviais extremos e das zonas de inundação}

12 A caracterização dos episódios pluviais extremos (impactos ligados às inundações, enchentes e alagamentos) pautou-se em dados secundários referentes aos seguintes aspectos: manchas históricas de inundações mapeadas para tempos de retorno de $10 \mathrm{e}$ 25 anos através do modelo Mike11, pelo Instituto das Águas do Paraná (2002 - antiga SUDERHSA); dados do Jornal Gazeta do Povo e relatórios de ocorrência do Sistema 
Informatizado de Defesa Civil (SISDC) no período de 1980 a 2015, bem como registros pontuais na temporalidade de 2005 a 2015 do Sistema de Gerenciamento da Guarda Municipal - SISGESGUARDA (SMDS, 2018).

Os eventos extremos e seus respectivos episódios foram validados por meio de consultas ao Jornal Gazeta do Povo, as quais foram realizadas tendo como base o limiar $48,6 \mathrm{~mm} / 24 \mathrm{~h}$, pautando-se no dia anterior ao evento, dia do evento e posterior ao evento extremo. A espacialização das ocorrências de impactos foi realizada a nível de bairros, permitindo identificar porções da cidade com maiores frequências de episódios extremos.

De modo conjugado, os dados pontuais de impactos, disponibilizados pela SISGESGUARDA, possibilitaram realizar mapeamentos através do estimador de Kernel no software ArcGIS 10.3, permitindo a identificação de densidades de ocorrências de episódios pluviais extremos no município.

\section{Mapeamento do cenário de vulnerabilidade}

Para a construção de um cenário de vulnerabilidade foram coletados dados relativos às condições de renda, educação e saneamento por setores censitários, segundo censo de 2010 do Instituto Brasileiro de Geografia e Estatística (IBGE, 2010). De modo a complementar a análise, levantamentos de invasões e ocupações irregulares (Silva M., 2012) também foram utilizados (Quadro 1). Para Almeida L. (2010) estas variáveis permitem identificar condições de vulnerabilidades das populações perante a problemas socioambientais, tais como as inundações urbanas.

O mapeamento da vulnerabilidade foi realizado por meio da análise multicritério e da técnica de cartografia de síntese, conforme procedimentos descritos por Martinelli M. (1991; 2003), Sampaio T. (2012), Buffon E. (2016) e Goudard G. (2019), através das etapas de normalização, padronização e ponderação de dados.

17 A normalização refere-se à relação de divisão entre duas variáveis, ao passo que a padronização leva em consideração os valores máximos e mínimos da amostra de dados e a amplitude total do conjunto de dados (Sampaio. T, 2012).

18 A atribuição de pesos às variáveis escolhidas foi feita com base em estudos de Almeida L. (2010), Nascimento E. (2013), Goudard G. (2015), Buffon E. (2016) e Goudard G. (2019), conforme expresso no Quadro 1. Estes estudos utilizaram-se de análises multicritério e ponderações para evidenciar vulnerabilidades sociais em diversas realidades espaciais.

Quadro 1 Variáveis e ponderações do cenário de vulnerabilidade

\begin{tabular}{|c|c|c|c|c|}
\hline Categoria & Peso & Subcategoria & Peso & Variáveis \\
\hline \multirow{2}{*}{$\begin{array}{l}\text { Características } \\
\text { dos moradores }\end{array}$} & \multirow{2}{*}{$40 \%$} & Alfabetização & $10 \%$ & Total de responsáveis não alfabetizados \\
\hline & & Renda & $30 \%$ & $\begin{array}{l}\text { Total responsável com renda até } 2 \text { salários } \\
\text { mínimos }\end{array}$ \\
\hline $\begin{array}{l}\text { Características } \\
\text { dos domicílios }\end{array}$ & $60 \%$ & $\begin{array}{l}\text { Rede de esgoto } \\
\text { ou fossa séptica }\end{array}$ & $10 \%$ & $\begin{array}{l}\text { Domicílios particulares permanentes sem rede } \\
\text { de esgoto ou fossa séptica }\end{array}$ \\
\hline
\end{tabular}




\begin{tabular}{|l|l|l|l|}
\hline $\begin{array}{l}\text { Moradia } \\
\text { Irregular }\end{array}$ & $30 \%$ & $\begin{array}{l}\text { Domicílios particulares permanentes em outra } \\
\text { condição de ocupação (não são próprios, } \\
\text { alugados e nem cedidos) }\end{array}$ \\
\hline Coleta de lixo & $20 \%$ & $\begin{array}{l}\text { Domicílios particulares permanentes sem } \\
\text { coleta de lixo, com depósito na propriedade, } \\
\text { em terreno baldio, logradouro, rio, lago ou } \\
\text { mar, ou outro destino }\end{array}$ \\
\hline
\end{tabular}

Fonte: IBGE (2010)

Organização: Goudard (2019)

Desse modo, por meio da cartografia de síntese e da álgebra de mapas entre as variáveis adotadas e ponderadas, fez-se possível evidenciar, espacialmente, as áreas de vulnerabilidades muito baixas a muito altas no município de Curitiba, bem como realizar análises integradas em relação às zonas mais afetadas por impactos ligados à pluviosidade, possibilitando a verificação das principais áreas de (e em) risco do município.

Ressalta-se que a compreensão das condições de vulnerabilidade concomitantemente às porções do município mais afetadas pelos extremos pluviais, possibilita a adoção de medidas de gestão de riscos mais eficientes no ambiente urbano, uma vez que permite o reconhecimento das áreas mais críticas em relação aos impactos de inundações urbanas na área de estudo.

\section{Curitiba: da "cidade modelo" à cidade permeada por condições de riscos e vulnerabilidades ligados às chuvas}

21 A cidade de Curitiba ainda que considerada planejada, ecológica e modelo de planejamento urbano, é marcada por diversos impactos de episódios pluviais extremos (inundações, enchentes e alagamentos) ao longo de sua história (Figura 2), em decorrência de quatro aspectos principais: 1) chuvas concentradas, 2) baixas declividades, 3) densa rede de drenagem, com modificações expressivas e 4) dinâmica de ocupação e expansão da cidade ao longo dos vales e confluências dos rios, desconsiderando o espraiamento das águas superficiais (Geissler H. e Loch R., 2004; Goudard G., 2015; 2019). 


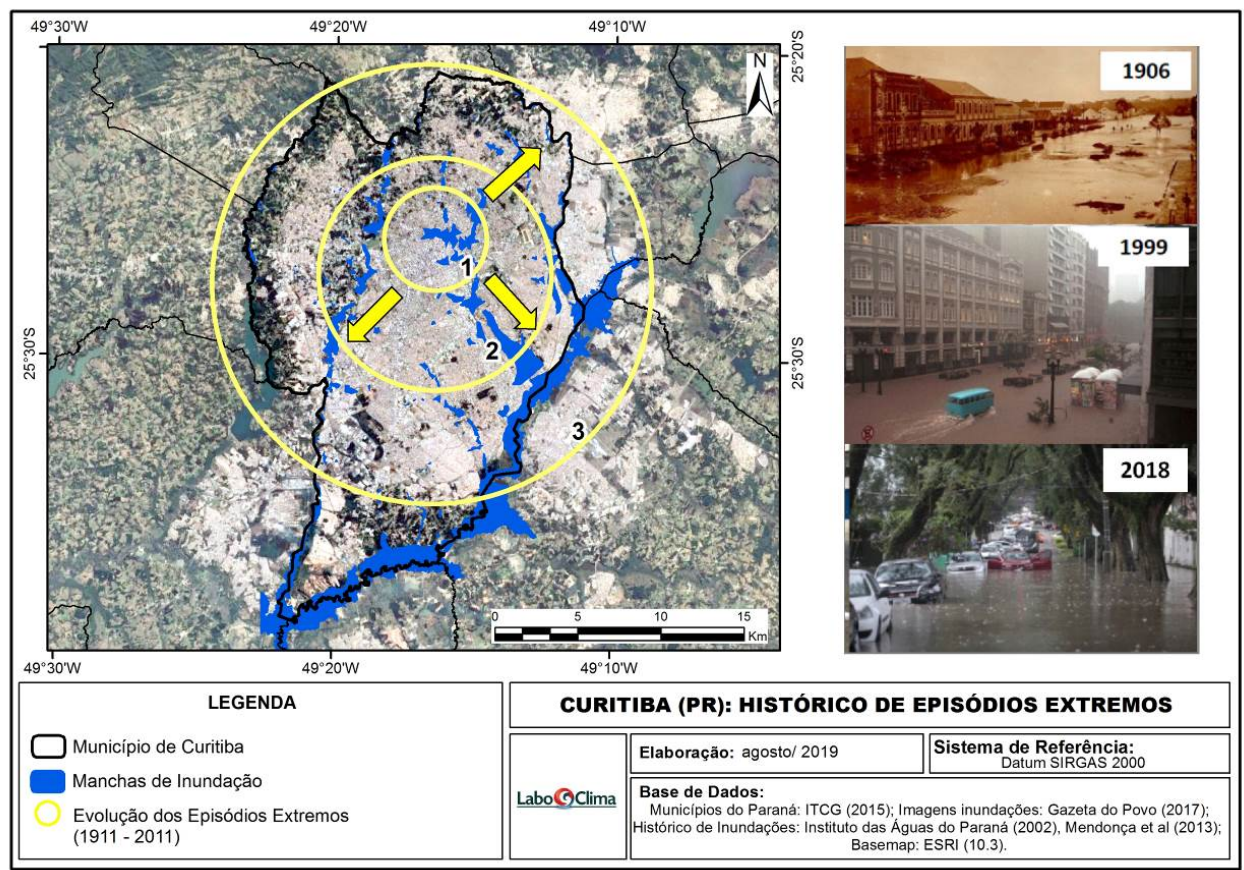

Organização: Goudard (2019)

Mendonça F., et al. (2013) ao realizarem uma análise histórica e crítica das manifestações de inundações no município em face das mudanças climáticas globais, constataram que tratam-se de processos recorrentes presentes desde os primórdios da fundação da cidade no final do século XVIII, sendo estes diferenciados em dois momentos: I) da fundação até meados do século XX apenas a porção central da cidade (1 - Figura 2) era fortemente impactada, culminando na realização de diversas obras por parte do poder público, cujo marco histórico foi a construção do Passeio Público, em 1886, no intuito de minimizar as repercussões negativas atreladas a estas dinâmicas no ambiente urbano; II) dos anos 1950 em diante as periferias geográficas (2 e 3 - Figura 2) passaram a serem impactadas com maiores frequências, devido à "exportação" dos problemas das áreas centrais e mediante o crescimento urbano destas porções espaciais, sem planejamento adequado. Dessa forma, para além das condições do meio físico que favorecem a deflagração desses processos em Curitiba, os impactos de episódios pluviais extremos, em grande parte, acompanharam o crescimento urbano do município e de sua região metropolitana (Mendonça F. et al., 2013; Goudard G., 2015; 2019).

Os impactos frequentes motivaram a realização de diversos estudos com o intuito de compreender a dinâmica e a espacialidade dos impactos em Curitiba, tais como o de Zanella M. (2006), no bairro Cajuru; Fortunato R. (2006) e Goudard G. e Mendonça F. (2018) na bacia do Rio Belém; Lohmann M. (2011) ao retratar os alagamentos no município no período de 2005 a 2010; Goudard G. (2015) ao analisar os eventos e episódios extremos em Curitiba de 1980 a 2010; Goudard G. (2019) ao evidenciar os riscos hidrometeorológicos híbridos na Bacia do Alto Iguaçu, englobando Curitiba e região metropolitana, entre outros. 

potencial de gerarem impactos) concentram-se, sobretudo, nos meses de verão (34\%), seguidos do outono (24\%), primavera (21\%) e inverno (20\%) na área de estudo. De acordo com análises de Goudard G. e Mendonça F. (2017) as concentrações espaciais destes eventos ocorrem na porção noroeste (acumulado e primavera), nordeste (outono) e leste (verão e inverno). Estas chuvas encontram-se associadas, ora às convecções intensas de verão, ora às oposições entre a Massa Tropical Atlântica (mTa) e Polar Atlântica (mPa), na forma de sistemas frontais (SF); e nas estações de transição, os Complexos Convectivos de Mesoescala (CCM's) também se expressam como importantes moduladores da pluviosidade na área (Grimm A., 2009). evidentes na temporada prolongada de verão e nas estações de transição, como corroboram as análises de Mendonça F. (2012), refletindo as condições temporais preferenciais associadas a estas ocorrências. Além disso, as chuvas desencadeadoras de impactos são bastante variadas, desde fortes e localizadas pancadas de chuva $(30 \mathrm{~mm}$, em poucos minutos/horas) até a ocorrência prolongada de precipitações (superiores a $30 \mathrm{~mm} / \mathrm{dia})$.

Em relação aos impactos destes eventos extremos, no recorte temporal do presente estudo (1980 a 2015) foram identificadas 51 ocorrências da Defesa Civil e 96.490 pessoas afetadas, de acordo com o relatório do Sistema Informatizado de Defesa Civil (SISDC). Em relação aos eventos extremos e seus retrospectos negativos no ambiente urbano, a partir dos registros combinados entre chuvas e as fontes documentais do Jornal Gazeta do Povo foram constatados 132 dias de chuvas extremas, das quais 84 deflagraram episódios pluviais extremos no município, com destaque para os meses de verão (DJF) e de transição, como setembro (Figura 3). 
Figura 3 Eventos (chuvas extremas) e episódios pluviais extremos (chuvas extremas que geraram impactos) em Curitiba (1980 - 2015)

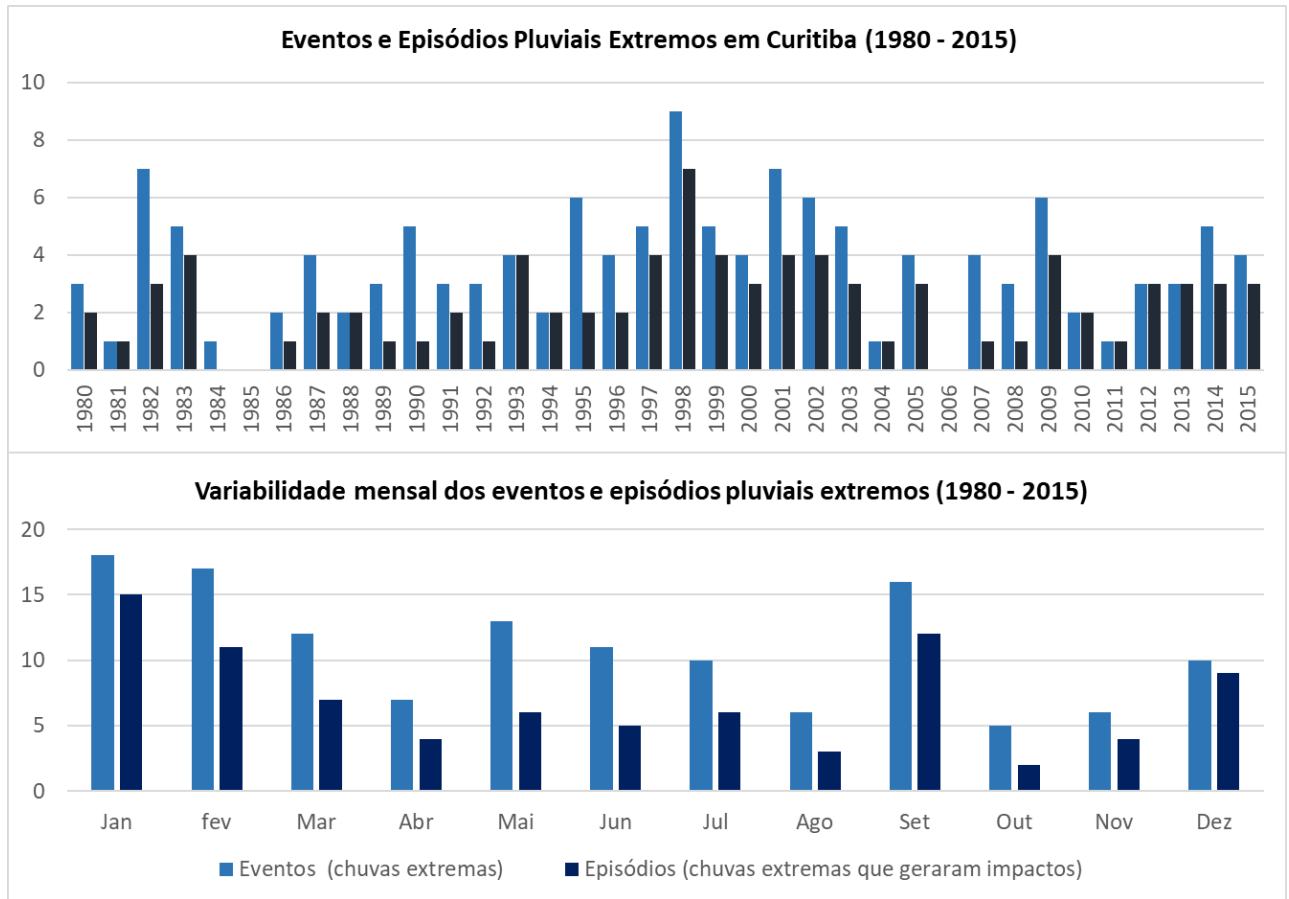

Organização: Goudard (2019)

Os episódios mais expressivos em termos de afetados, tendo como base os dados de jornais e os relatórios de ocorrências de Defesa Civil, são evidenciados no Quadro 2, com destaque para o dia 21/02/1999, no qual foram registradas chuvas de $146,2 \mathrm{~mm}$ em 2 horas, culminando em impactos significativos em 13 bairros da cidade.

Quadro 2 Episódios pluviais extremos, tipos de tempo e pessoas afetadas (1980 - 2015)

\begin{tabular}{|l|l|l|l|l|l|}
\hline \multirow{2}{*}{ Data } & \multicolumn{2}{|l|}{ Pluviosidade } & Sistema & Pessoas \\
\cline { 2 - 5 } & $\begin{array}{l}\text { (mm/ } \\
\text { evento) }\end{array}$ & $\begin{array}{l}\text { (mm/ } \\
\text { mês) }\end{array}$ & Atmosférico & Afetadas & Manchete dos Jornais \\
\hline $31 / 11 / 1981$ & 52,4 & 136,9 & SF & 600 & $\begin{array}{l}\text { Enchente deixa 3 mil sem teto e } \\
\text { muitos prejuízos }\end{array}$ \\
\hline 22 & 88,7 & - & SF & 300 & $\begin{array}{l}\text { Desabrigados e prejuízos com o } \\
\text { excesso de chuva }\end{array}$ \\
\hline $13 / 03 / 1991$ & 52,8 & 156,5 & SF & 70 & $\begin{array}{l}\text { Famílias vivem um drama com o } \\
\text { temporal }\end{array}$ \\
\hline $21 / 09 / 1993$ & 103,3 & 357,2 & SF & 3.000 & $\begin{array}{l}\text { Chuvas desabrigam 3 mil em } \\
\text { Curitiba }\end{array}$ \\
\hline $10 / 01 / 1997$ & 74,6 & 403,3 & $\begin{array}{l}\text { ZCAS (mEc) } \\
\text { SF }\end{array}$ & 2 mortes & $\begin{array}{l}\text { Temporal provoca o caos em } \\
\text { Curitiba/ Curitiba avalia prejuízos } \\
\text { causados pela chuva }\end{array}$ \\
\hline
\end{tabular}




\begin{tabular}{|c|c|c|c|c|c|}
\hline $\begin{array}{l}11 \quad \text { e } \\
12 / 02 / 1997\end{array}$ & 132,9 & 232,9 & SF & 1.000 & Chuvas voltam a causar inundações \\
\hline $21 / 02 / 1999$ & 146,2 & 445,2 & $\begin{array}{l}\text { ZCAS (mEc) e } \\
\text { SF }\end{array}$ & 15.000 & $\begin{array}{l}\text { Chuva de duas horas traz o caos a } \\
\text { Curitiba / Curitiba vive um } \\
\text { domingo de inundação }\end{array}$ \\
\hline $12 / 09 / 2000$ & 57,9 & 249,1 & SF & 2.000 & $\begin{array}{l}\text { Chuva causa estragos em Curitiba e } \\
\text { RMC / Chuvas causam mais } \\
\text { destruição e desalojados já passam } \\
\text { de } 2 \text { mil }\end{array}$ \\
\hline $\begin{array}{l}20 \quad \text { e } \\
21 / 06 / 2013\end{array}$ & 137,9 & 319,0 & SF & 8.545 & $\begin{array}{l}\text { Chuvas deixam } 2 \text { mortos e } 502 \\
\text { desalojados no Paraná }\end{array}$ \\
\hline $07 / 06 / 2014$ & 95,2 & 210,4 & SF & 16.804 & $\begin{array}{l}\text { Prefeito de Curitiba decreta estado } \\
\text { de alerta por conta de temporais }\end{array}$ \\
\hline $22 / 12 / 2014$ & 47,6 & 155,6 & SF & 41.700 & $\begin{array}{l}\text { Chuva atinge } 44 \text { mil pessoas em } \\
\text { todo o Paraná }\end{array}$ \\
\hline $04 / 02 / 2015$ & 54,3 & 243,1 & $\begin{array}{l}\text { ZCAS (mEc) e } \\
\text { SF }\end{array}$ & 1.960 & $\begin{array}{l}\text { Chuva causa alagamentos e deixa } \\
22 \text { mil casas sem luz em Curitiba e } \\
\text { região }\end{array}$ \\
\hline $27 / 05 / 2015$ & 27,9 & 115,1 & SF & 7.188 & $\begin{array}{l}\text { Chuva provoca alagamentos em } \\
\text { Curitiba }\end{array}$ \\
\hline
\end{tabular}

Fonte: Hidroweb, Defesa Civil, Jornal Gazeta do Povo, Cartas Sinóticas da Marinha do Brasil e CPTEC (2018).

Organização: Goudard (2019)

30 A análise do Quadro 2 permite evidenciar que os Sistemas Frontais (SF), marcados pela oposição entre massas de características térmicas, de umidade e pressão distintas, configuram-se como os principais desencadeadores das excepcionalidades climáticas ligadas às chuvas na área. As incursões destes sistemas ocorrem durante o ano todo na região sul do país, com 30 a 45 passagens médias anuais, desestabilizando a atmosfera e gerando pluviosidade (Cavalcanti I. e Kousky V., 2009). Em alguns casos também se evidenciam contribuições dos sistemas de ZCAS (Zona de Convergência do Atlântico Sul), uma banda de nebulosidade entre a região Norte e Sudeste-Sul do país (Carvalho L. e Jones C., 2009).

31 As zonas de inundação (Figura 4c) expressam as condições de suscetibilidade, as quais referem-se à relação de atributos físicos que refletem a probabilidade espacial de ocorrência de um determinado fenômeno, tais como as baixas declividades e proximidades de rios no que tange aos riscos de inundações (Zêzere J. et al., 2005). Neste contexto, verifica-se que as bacias do Belém (compreendendo o centro da cidade), do Barigui, do Ribeirão dos Padilhas e Atuba são as mais suscetíveis ao acúmulo de água e aos potenciais impactos de episódios pluviais extremos (Figura 4c). Estes fatores, de ordem natural, são agravados ao se considerar as impermeabilizações e as modificações 
expressivas nas redes de drenagem que foram realizadas nestas bacias ao longo do tempo.

A espacialização das manchas de inundação (Figura 4c), de modo conjugado aos registros de impactos provenientes dos jornais (1980 - 2015) - (Figura 4a) e à densidade das notificações pontuais da Defesa Civil (2005 - 2015) - Figura 4b, permitem constatar que algumas áreas da cidade, notadamente, as porções central, oeste e leste são recorrentemente afetadas por impactos ligados aos extremos de chuva. Dessa forma, os bairros do Centro, Cidade Industrial, Boqueirão, Uberaba, Cajuru e Hauer destacam-se como os mais impactados (Figura 4a), com variações de 16 a 29 casos no recorte temporal da presente análise.

Figura 4 Áreas afetadas por episódios pluviais extremos no município de Curitiba

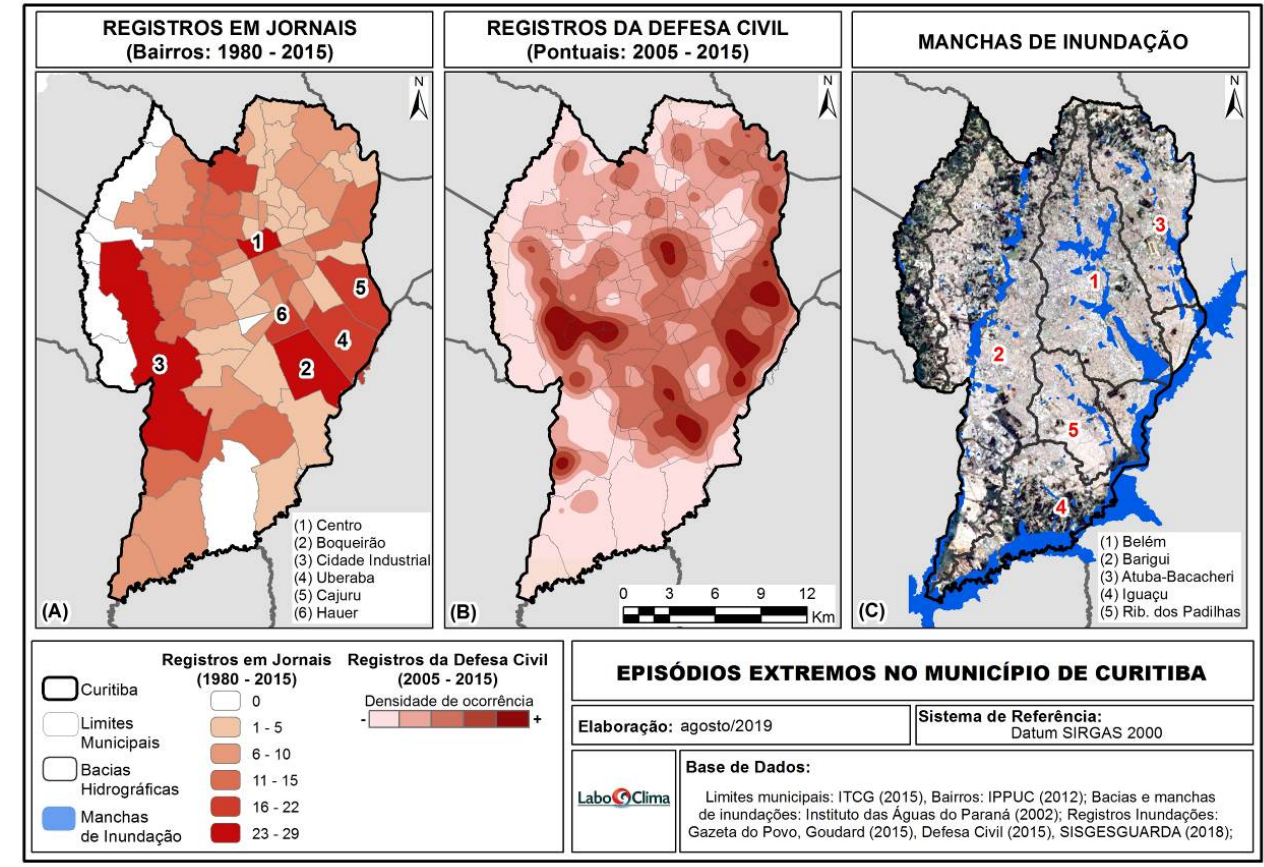

Organização: Goudard (2019)

Salienta-se ainda que os casos pontuais de impactos (Figura $4 \mathrm{~b}$ ) corroboram com este cenário, de maiores concentrações de densidade de episódios pluviais extremos no Centro, na porção leste do município (bairros Uberaba, Cajuru, Boqueirão) e na Cidade Industrial (oeste), evidenciando a recorrência destes processos no âmbito destas porções da cidade.

Cabe ressaltar, que ainda que sob as mesmas condições de excepcionalidades climáticas (chuvas extremas) e suscetibilidades (baixas declividades e ocupações próximas aos rios, refletidas por meio do mapeamento de zonas de inundação), as populações não são atingidas de maneiras iguais por estes episódios, refletindo diferentes condições de vulnerabilidade. A vulnerabilidade é expressa por Pelling M. (2003) como a heterogeneidade dos impactos advindos dos riscos que se abatem sobre uma dada população, estando associada à exposição, resistência e resiliência; e refletindo a (in)capacidade de reação e dificuldade de adaptação diante da materialização do risco. De modo semelhante, Marandola Junior E. (2009) e Mendonça F. (2010) reiteram que se 
tratam de diferentes condições de exposição e de fragilidade de grupos sociais aos riscos.

Neste sentido, do ponto de vista das condições de vulnerabilidade ao longo do município (Figura 5), notam-se em algumas áreas da cidade coincidências entre as zonas suscetíveis a impactos de episódios pluviais extremos (zonas de inundação e registros de impactos) e áreas de alta vulnerabilidade, com a concentração de ocupações irregulares. De um modo geral, conforme nota-se na Figura 5, a porção leste, na confluência com os municípios de Pinhais e São José dos Pinhais; e parcelas da bacia do Barigui se destacam, com condições de alta vulnerabilidade e sujeitas às inundações. Estes processos são decorrentes, sobretudo, do fato de que as populações com menores condições de vida se sujeitam a viver em áreas de risco nos ambientes urbanos (notadamente a porção leste da cidade, em partes da Bacia do Belém e em parcelas da bacia do Barigui, no bairro Cidade Industrial).

Além disso, por meio da análise da figura 5 , constata-se que as condições de moderada a muito alta vulnerabilidade ampliam-se à medida em que ocorrem distanciamentos da região centro-norte da cidade, em direção às periferias geográficas. Estas condições reiteram as afirmações de Deschamps M. (2004), Zanella M. (2006), Cunico C. (2013) e Goudard G. (2015) ao retratarem que os episódios extremos ocorrem e impactam de modo heterogêneo a cidade, verificando-se, em alguns bairros, coincidências entre as áreas de suscetibilidade natural (zonas inundáveis, próximas aos rios) e vulnerabilidade social (populações com menores condições de renda a acesso a serviços de saneamento), ampliando as condições de riscos em algumas regiões do município.

Figura 5 Condições de vulnerabilidade no município de Curitiba

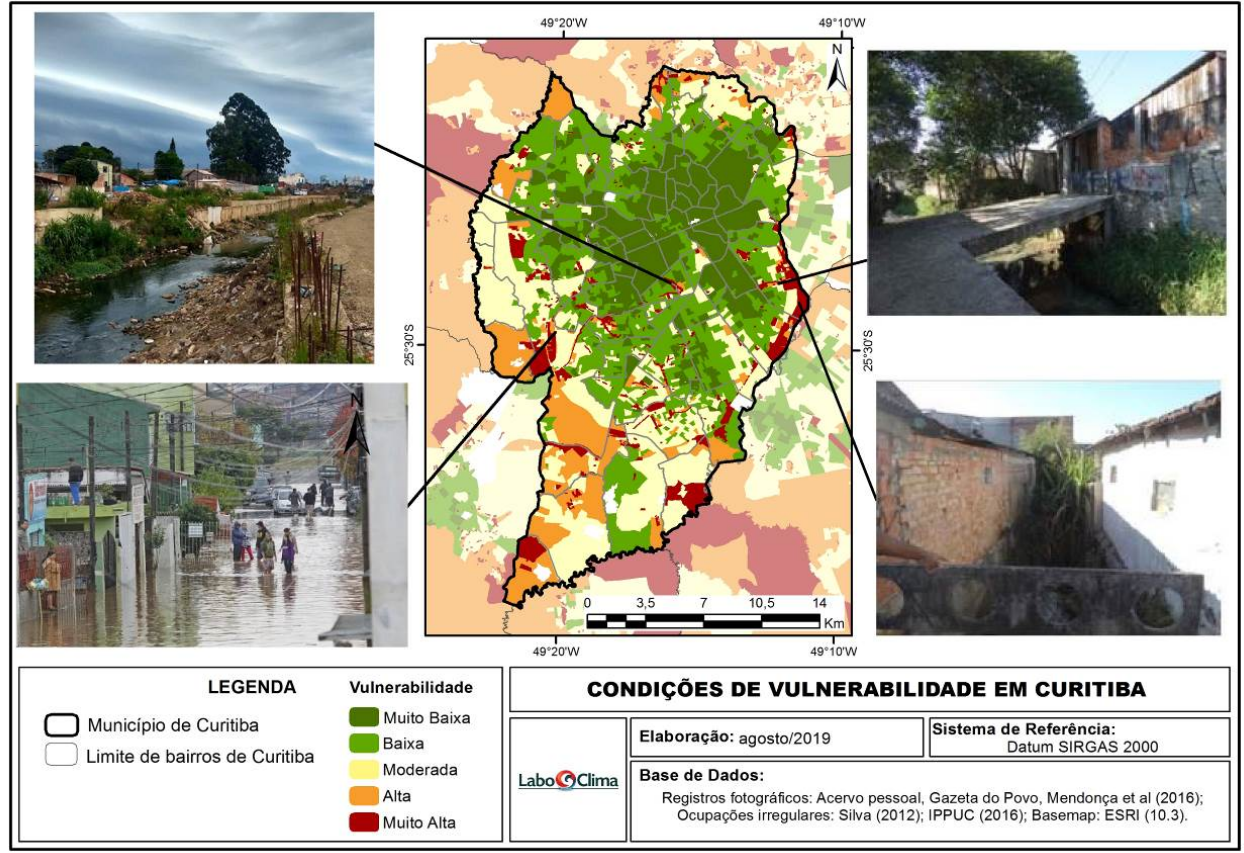

Organização: Goudard (2019)

Para Deschamps M. (2004) estas dinâmicas são explicadas mediante ao fato de que a demanda por solo para a expansão da cidade provoca o aproveitamento de terras impróprias e expostas a riscos naturais, de modo que, as dificuldades enfrentadas pela 
população de mais baixa renda -em condições de maior vulnerabilidade social- as obriga a instalar-se em áreas de risco, potencializando ainda mais o seu grau de vulnerabilidade perante a estes processos.

Dessa forma, partindo-se dos pressupostos destacados por Birkmann J. (2007) ao afirmar que uma abordagem integrada e holística dos riscos pressupõe o reconhecimento de três pontos norteadores, quais sejam: os mais vulneráveis, os espaços expostos a risco; e os fatores que influenciam e produzem vulnerabilidade/ risco, ressalta-se que na cidade de Curitiba os impactos históricos e recorrentes ligados às chuvas não podem ser analisados de maneira dissociada. Assim, fazem-se necessárias análises integradas que considerem a variabilidade das condições climáticas e suas excepcionalidades (eventos pluviais extremos), as suscetibilidades atreladas a atributos físicos (zonas sujeitas às inundações) e às vulnerabilidades sociais, sendo estes processos articulados e eivados de complexidades.

\section{Considerações finais: os desafios da abordagem dos riscos em áreas urbanas no Brasil}

A cidade de Curitiba apresenta um histórico significativo de impactos ligados às chuvas, estando estes associados às condicionantes do clima (eventos pluviais extremos), às condições de suscetibilidade (baixas declividades, alta densidade de ocupações às margens dos rios e modificações dos canais fluviais, zonas inundáveis) e vulnerabilidade (diferentes graus de exposição aos riscos). Ressalta-se que a análise destes processos e as medidas de gestão em relação aos riscos hidrometeorológicos vêm apresentando diversos avanços, contudo alguns desafios em relação às suas aplicações, sobretudo, em ambientes urbanos altamente modificados, ainda dificultam abordagens dos riscos em escalas refinadas e de maneiras integradas.

$40 \mathrm{Na}$ atualidade, os avanços tecnológicos, sobretudo, no que se refere ao Sistema de Informações Geográficas (SIG) vêm proporcionando melhores compreensões das configurações espaço-temporais dos riscos, tanto em face da espacialização dos dados de cunho geográfico, como da multiplicidade de modelos que permitem evidenciar, no tempo e no espaço, os processos associados a estas dinâmicas.

41 Contudo, alguns desafios ainda encontram-se presentes na abordagem integrada dos riscos climáticos em ambientes urbanos, entre os quais quatro principais merecem destaque, quais sejam:

1) escala temporal dos dados climáticos,

2) modelos para mapeamentos de suscetibilidade e espacialização de zonas inundáveis,

3) dados atrelados à vulnerabilidade $e$

4) metodologias para a compreensão dos riscos em contextos metropolitanos.

No que se refere aos dados climáticos, notadamente pluviais, verifica-se uma carência de séries históricas com recortes temporais horários no Brasil. Este fato dificulta a compreensão das variabilidades espaço-temporais das chuvas desencadeadoras de impactos, uma vez que impactos decorrentes de precipitações concentradas em poucos minutos, acabam sendo mascarados em séries de dados diárias (amplamente utilizadas em estudos do clima). Em Curitiba, as séries horárias do CEMADEN (Centro Nacional de Monitoramento e Alertas de Desastres Naturais) com boa espacialização são bastante recentes, datadas de 2013 até os dias atuais. Salienta-se que a utilização de dados 
horários possibilitaria melhores compreensões da relação de tempo de ocorrência dos impactos, permitindo medidas mais efetivas em relação à gestão de riscos de origem pluvial.

Os mapeamentos de suscetibilidade e os modelos de zonas de inundação também se configuram como desafios em face destas temáticas, visto que são produzidos, em geral, com base nas dinâmicas fluviais e em atributos físicos (hipsometria, declividade, solos, entre outros). No contexto dos ambientes urbanos, muitos impactos são decorrentes de alagamentos, ligados à impermeabilização excessiva, de modo que muitos destes mapeamentos não possibilitam detalhamentos das áreas potenciais de impacto, mas apenas aproximações em relação às zonas preferenciais de acúmulo de água, com base na dinâmica fluvial. Dessa forma, modelos adaptados às condições urbanas, levando em consideração atributos para além dos físico-naturais, possibilitariam melhores respostas em relação às áreas potencialmente inundadas nas cidades.

No que se refere à vulnerabilidade, no Brasil, em grande parte, os dados sociais são provenientes dos censos do IBGE, com atualizações de $10 \mathrm{em} 10$ anos. Este fato dificulta análises mais detalhadas das alterações de variáveis sociais ao longo do tempo, sobretudo, em áreas urbanas com modificações bastante rápidas.

Além disso, em realidades de metropolização, tais como a de Curitiba e região metropolitana, as análises dos riscos são realizadas de maneira isolada, em escalas municipais, inviabilizando medidas integradas entre os municípios, conforme destacam Buffon E. et al. (2017). Assim, em muitos casos medidas adotadas em algumas áreas, acabam por transferir os impactos para zonas e municípios a jusante. Neste sentido, reitera-se a necessidade de estudos integrados em contextos metropolitanos, visto que os riscos climáticos e hidrometeorológicos não respeitam os limites municipais.

Partindo-se destas premissas, no que se refere à análise de riscos climáticos em contextos urbanos, como o apresentado neste estudo de caso para a cidade de Curitiba, faz-se necessário considerar as condições sinóticas deflagradoras de chuvas extremas, os processos de suscetibilidade do meio físico (zonas sujeitas às inundações, incorporando aspectos de modificação urbana, tais como impermeabilizações e modificações nas redes de drenagem) e as diferentes condições de vulnerabilidade das populações atingidas por esses processos. Estas dinâmicas, de maneira integrada, possibilitam contribuições à gestão de riscos de ordem climática nos ambientes urbanos, visto que permitem identificar as áreas críticas em relação aos impactos e aos impactados no âmbito das cidades, contribuindo para o planejamento urbano.

\section{BIBLIOGRAFIA}

Almeida, Lutiane Queiróz. Vulnerabilidades socioambientais de rios urbanos: bacia hidrográfica do rio Maranguapinho, região metropolitana de Fortaleza, Ceará. 278 f. Tese (Doutorado em Geografia) Instituto de Geociências e Ciências Exatas, Universidade Estadual Paulista, Rio Claro, 2010. 
Alvares, Clayton Alcarde, et al. « Koppen's climate classification map for Brazil » Meteorologische Zeitschrift, Vol. 22, nº. 6, 711-728, 2013.

Armond, Núbia Beray. Entre Eventos e Episódios: as excepcionalidades das chuvas e os alagamentos no espaço urbano do Rio de Janeiro. 239f. Dissertação (Mestrado em Geografia) - Faculdade de Ciências e Tecnologia, Universidade Estadual Paulista Júlio de Mesquita Filho, Presidente Prudente, 2014.

Beck, Ulrich. La sociedad del riesgo mundial: em busca de la seguridad perdida. Barcelona: Paidós Ibérica, 2008.

Birkmann, Joern. « Risk and vulnerability indicators at different scales: Applicability, usefulness and policy implications » Environmental hazards, v. 7, n. 1, p. 20-31, 2007.

Buffon, Elaiz Aparecida Mensch. A leptospirose humana no AU-RMC (Aglomerado Urbano da Região Metropolitana de Curitiba/PR) - risco e vulnerabilidade socioambiental. 172f. Dissertação (Mestrado em Geografia) - Setor de Ciências da Terra, Universidade Federal do Paraná, 2016.

Buffon, Elaiz Aparecida Mensch, Goudard, Gabriela, Mendonça, Francisco de Assis. « Gestão de risco de desastres e medidas de adaptação em áreas de inundação urbana em Pinhais, Paraná Brasil » Revista Brasileira de Cartografia, № 69/4, Edição Desastres Naturais e Impactos Ambientais, 2017, p. 635-646.

Carvalho, Leila Maria V. de Carvalho, Jones, Charles. « Zona de Convergência do Atlântico Sul » in Cavalcanti, Iracema Fonseca de Albuquerque, et al. (eds) Tempo e Clima no Brasil. São Paulo, Oficina de Textos. 2009, p. 95 - 109.

Cavalcanti, Iracema Fonseca de Albuquerque, Kousky, Vernon E. « Frentes Frias sobre o Brasil » in Cavalcanti, Iracema Fonseca de Albuquerque, et al. (eds). Tempo e Clima no Brasil. São Paulo, Oficina de Textos. 2009, p. 135-148.

Cunico, Camila. Do risco à adaptação: a identificação da vulnerabilidade socioambiental de Curitiba - PR. 288f. Tese (Doutorado em Geografia) - Setor de Ciências da Terra, Universidade Federal do Paraná, Curitiba, 2013.

Dauphiné, André. Risques et catastrophes - Observer, spatialiser, comprendre, gérer. Paris, Armand Colin, 2001.

Deschamps, Marley Vanice. Vulnerabilidade socioambiental na região metropolitana de Curitiba/PR. Tese (Doutorado em Meio Ambiente e Desenvolvimento) - Universidade Federal do Paraná, Curitiba, 2004.

Dubois-Maury, Jocelyne, Chaline, Claude. Les risques urbains. Paris, Armand Colin, 2004.

EM-DAT. Emergency Events Database. Annual disaster statistical review. 2015.

Fortunato, Rafaela Antunes. Subsídios à Preservação e Controle das Inundações Urbanas: Bacia Hidrográfica do Rio Belém, Município de Curitiba - PR. 237 f. Dissertação (Mestrado em Construção Civil) - Setor de Tecnologia, Universidade Federal do Paraná, Curitiba, 2006.

Geissler, Helenne Jungblut, Loch, Ruth Emília Nogueira. Análise Histórica das enchentes em CuritibaPR, Medidas Propostas e consequências observadas. Florianópolis, UFSC, 2004.

Goudard, Gabriela. Eventos e Episódios Pluviais Extremos em Curitiba (PR): uma abordagem a partir dos riscos e vulnerabilidades socioambientais. $129 \mathrm{f}$. Trabalho de Conclusão de Curso (Bacharelado em Geografia) - Setor de Ciências da Terra, Universidade Federal do Paraná. Curitiba, 2015.

Goudard, Gabriela, Mendonça, Francisco de Assis. « Eventos pluviais extremos em Curitiba (Paraná): entre antigos problemas e novos desafios » in Perez Filho, Archimedes, Amorim, Raul 
Reis. (eds.). Os desafios da Geografia Física na Fronteira do Conhecimento. $1^{1 \mathrm{a}}$ ed. Campinas, Instituto de Geociências - UNICAMP, 2017, vol. 1, p. 1919-1930.

Goudard, Gabriela, Mendonça, Francisco de Assis. « Les inondations urbaines à Curitiba (Brésil): risques et impacts dans le bassin versant de la rivière Belém » in Actes du XXXI Colloque Annuel de l'Association Internationale de Climatologie. Université de Nice Sophia Antipolis, Nice, 2018, vol. 1. p. 104-109.

Goudard, Gabriela. Eventos pluviais extremos e riscos hidromeorológicos híbridos na Bacia do Alto Iguaçu (Paraná). 236f. Dissertação (Mestrado em Geografia). Programa de pós-graduação em Geografia Setor de Ciências da Terra, Universidade Federal do Paraná, Curitiba, 2019.

Grimm, Alice Marlene. Clima da região Sul do Brasil. in Cavalcanti, Iracema Fonseca de Albuquerque, et al. (eds). Tempo e clima no Brasil. Oficina de Textos. 2009, p. 260 -275.

HIDROWEB. Sistemas de Informações Hidrológicas da Agência Nacional de Águas (ANA). http:// www.snirh.gov.br/hidroweb/, acesso em: julho de 2017.

IBGE. Instituto Brasileiro de Geografia e Estatística - Censo 2010. http://www.ibge.gov.br/home/ estatistica/populacao/censo2010. 2010, acesso em: abril de 2018.

IPCC. Intergovernmental Panel on Climate Change: Climate Changes - The physical science basis. Summary of Policymakers, 2007.

IPCC. Climate Change - The Physical Science Basis. Summary for Policymakers - Technical Summary, Intergovernmental Panel on Climate Change, 2013. https://www.ipcc.ch/pdf/ assessment-report/ar5/wg1/WG1AR5_SummaryVolume_FINAL.pdf, acesso em: outubro de 2015.

Lohmann, Marciel. Regressão logística e redes neurais aplicadas à previsão probabilística de alagamentos no município de Curitiba, PR. 230f. Tese (Doutorado em Geografia) - Programa de Pós-Graduação em Geografia, Universidade Federal do Paraná, Curitiba, 2011.

Marandola Junior, Eduardo. Tangenciando a vulnerabilidade. in Hogan, Daniel Joseph.; Marandola Jr., Eduardo. População e mudança climática. Dimensões humanas das mudanças ambientais globais. Campinas: Núcleo de Estudos de População-Nepo/ Unicamp; Brasília: UNFPA, 2009, p. 29 - 52.

Martinelli, Marcello. Curso de cartografia temática. 1. ed. São Paulo: Contexto, 1991.

Martinelli, Marcello. Mapas da geografia e cartografia temática. São Paulo: Contexto, 2003.

Mendonça, Francisco de Assis. S.A.U. - Sistema Ambiental Urbano: uma abordagem dos problemas socioambientais da cidade. in Mendonça, F. (eds.) Impactos Socioambientais Urbanos. Curitiba: Editora UFPR, 2004.

Mendonça, Francisco de Assis. Riscos e Vulnerabilidades socioambientais urbanos a contingência climática. Mercator, v 9, n.1, p.153-163, dez/2010.

Mendonca, Francisco de Assis. Les inondations urbaines à Curitiba (Brésil). in XXV Colloque de l'AIC - Association internationale de climatologie, Grenoble. Actes du XXV Colloque de l'AIC. Grenoble: Univ Grenoble. v. 1. 2012, p. 517- 523.

Mendonça, Francisco de Assis, Deschamps, Marley Vanice, Lima, Myrian Del Vecchio de, «A cidade e as mudanças climáticas globais: (intensificação?) - Riscos e Vulnerabilidades Socioambientais na RMC - Região Metropolitana de Curitiba/PR » in Ojima, Ricardo, Marandola Jr, Eduardo. Mudanças Climáticas e as Cidades: novos e antigos debates na busca da sustentabilidade urbana e social. Blucher, Coleção População e Sustentabilidade, 2013, p.129 -162.

Monteiro, Carlos Augusto de Figueiredo. Teoria e Clima Urbano. 191f. Tese (Livre Docência em Geografia) - Universidade de São Paulo, São Paulo, 1976. 
Monteiro, Carlos Augusto de Figueiredo. Clima e Excepcionalismo: conjecturas sobre o desempenho da atmosfera como fenômeno geográfico. Florianópolis, Editora da UFSC, 1991.

Nascimento, Ederson, As desigualdades socioespaciais urbanas numa metrópole interiorana: uma análise da região metropolitana de Campinas (SP) a partir de indicadores de exclusão/ inclusão social. $273 \mathrm{f}$. Tese (Doutorado em Geografia) - Instituto de Geociências, Universidade Estadual de Campinas, 2013.

Nimer, Edmon, Climatologia do Brasil. Instituto Brasileiro de Geografia e Estatística, Rio de Janeiro, 1979.

Pelling, Mark. The vulnerability of cities: natural disaster and social resilience. London, Earthscan, 2003.

Pinheiro, Gabriela Marques. Variabilidade temporo-espacial da pluviosidade na bacia do alto Iguaçu. 274 f. Tese (Doutorado em Geografia) - Programa de Pós-Graduação em Geografia, Setor de Ciências da Terra, Universidade Federal do Paraná, Curitiba, 2016.

Sampaio, Tony Vinicius Moreira. Diretrizes e procedimentos metodológicos para a cartografia de síntese com atributos quantitativos via álgebra de mapas e análise multicritério. Boletim de Geografia, Maringá, v. 30, n. 1, p. 121-131, 2012.

Secretaria Municipal da Defesa Social (SMDS), Relatório de Ocorrência Natural Atendida. (SiGesGuarda), 2018, defesasocial.curitiba.pr.gov.br/, acesso em outubro de 2018.

Silva, Madianita Nunes da, A dinâmica de produção dos espaços informais de moradia e o processo de metropolização em Curitiba. 259 f. Tese (Doutorado em Geografia) - Setor Ciências da Terra, Universidade Federal do Paraná, Curitiba, 2012.

Silveira, Wivian Nereida, K, et al., História das inundações em Joinville (1851-2008). Curitiba, PR: Organic Trading, 2009.

SUDERHSA. Plano Diretor de Drenagem da Bacia do Alto Iguaçu na Região Metropolitana de Curitiba. Superintendência de desenvolvimento de recursos hídricos e saneamento ambiental, 2002.

Veyret, Yvette. Os Riscos: o homem como agressor e vítima do meio ambiente. São Paulo, Contexto, 2007.

Zanella, Maria Elisa. Inundações Urbanas em Curitiba/PR: Impactos, Riscos e Vulnerabilidade Socioambiental no Bairro Cajuru. 272 f. Tese (Doutorado em Meio Ambiente e Desenvolvimento) Setor de Ciências da Terra, Universidade Federal do Paraná, Curitiba, 2006.

Zêzere, José Luís. Análise sensitiva na avaliação da susceptibilidade a deslizamentos na região a norte de Lisboa. Centro de Estudos Geográficos, Universidade de Lisboa. 2005.

\section{RESUMOS}

O presente artigo apresenta como objetivo analisar os riscos hidrometeorológicos em Curitiba, colocando em evidência as condicionantes climáticas atreladas à ocorrência de eventos e episódios extremos, as zonas de inundação e as áreas de vulnerabilidade. Para tanto, utiliza-se de dados pluviais, de áreas inundáveis e de variáveis sociais de maneira integrada. Os resultados encontrados configuram-se como subsídios à gestão de riscos climáticos ligados à pluviosidade em ambientes urbanos.

This paper presents the objective of analyzing the hydrometeorological risk in Curitiba, highlighting the climatic conditions linked to the occurrence of extreme events and episodes, flood zones and vulnerable areas. For that, it uses rain data, flooded areas and social variables in 
an integrated manner. The results found are configured as subsidies to the management of climatic risks linked to rainfall in urban environments.

Cet article analyse les risques hydrométéorologiques à Curitiba, en mettant en évidence les conditions climatiques liées à la survenue d'événements et d'épisodes extrêmes, de zones inondables et de zones vulnérables. Pour cela, il utilise les données pluviométriques, les zones inondées et les variables sociales de manière intégrée. Les résultats trouvés contribuent à la gestion des risques climatiques liés aux précipitations en milieu urbain.

Este artículo tiene como objetivo analizar los riesgos hidrometeorológicos en Curitiba, destacando las condiciones climáticas vinculadas a la ocurrencia de eventos y episodios extremos, las zonas de inundación y las áreas vulnerables. Para eso, utiliza datos de lluvia, áreas inundadas y variables sociales de manera integrada. Los resultados encontrados subsidian la gestión de riesgos climáticos vinculados a la lluvia en entornos urbanos.

\section{ÍNDICE}

Mots-clés: variabilité pluviale, événements de pluie extrême, inondations urbaines, risques hydrométéorologiques, Curitiba

Palavras-chave: variabilidade pluvial, eventos pluviais extremos, inundações urbanas, riscos hidrometeorológicos, Curitiba

Keywords: pluvial variability, extreme rain events, urban floods, hydrometeorological risks, Curitiba

Palabras claves: variabilidad de la lluvia, eventos de lluvia extrema, inundaciones urbanas, riesgos hidrometeorológicos, Curitiba.

\section{AUTORES}

\section{GABRIELA GOUDARD}

Gabriela Goudard é doutoranda em Geografia pelo programa de pós-graduação da Universidade Federal do Paraná (UFPR - Brasil). Pesquisadora no Laboratório de Climatologia (LABOCLIMA/ UFPR) - Centro Politécnico - Ed. João José Bigarella, sala 210, Curitiba, Brasil.gabigoudard.ufpr@gmail.com

\section{FRANCISCO DE ASSIS MENDONÇA}

Francisco de Assis Mendonça é Professor Titular do Departamento de Geografia da Universidade Federal do Paraná. Laboratório de Climatologia (LABOCLIMA/UFPR) - Centro Politécnico - Ed. João José Bigarella, sala 210, Curitiba, Brasil. chico@ufpr.br 